\title{
Multicenter Implementation of a New Electronic Medical Record System Leads to Longer Procedure Times and Poor Staff Satisfaction
}

\author{
Andrew C. Storm, Marvin Ryou and Christopher C. Thompson \\ Division of Gastroenterology, Hepatology \& Endoscopy, Brigham and Women's Hospital, Harvard Medical School, Boston, MA, USA
}

Electronic health record (EHR) systems have become a mainstay for housing and communicating clinical patient data, since the U.S. federal government mandated their implementation in 2014. ${ }^{1}$ Several EHR systems have come to the forefront in popularity, with the leader being Epic (Epic Systems Co., Verona, WI, USA). Such systems are costly, but improve capture of charges for a medical system through built-in requirements on physician and nurse users to order and document services, link diagnoses, and associate billing levels with each encounter. ${ }^{2}$ Prior studies have suggested a strain on providers from these EHR requirements, especially at the time of initial implementation. ${ }^{3}$ Inpatient safety has also been shown to improve after EHR implementation, but house staff job satisfaction has been impacted negatively by the time spent navigating the $\mathrm{EHR}^{4,5}$

In the endoscopy suite, there is little room for distraction due to constant monitoring of sedated patients and the procedural task load on assisting staff (including biopsy and polypectomy, among others). Our hypothesis was that implementing and learning a new EHR based on increased user input could, at a minimum, exert strain on staff, and in the worst case lead to distracted staff. Our aim was to measure patient safety and staff satisfaction in the endoscopy suite across practice settings including a tertiary care hospital, a community hospital, and an outpatient endoscopy unit during and after

Received: May 10, 2018 Revised: July 7, 2018

Accepted: July 9, 2018

Correspondence: Andrew C. Storm

Division of Gastroenterology, Hepatology \& Endoscopy, Brigham and Women’s Hospital, 75 Francis Street, Boston, MA 02115, USA

Tel: +1-507-284-2511, Fax: +1-507-538-7724, E-mail: storm.andrew@mayo.edu ORCID: https://orcid.org/0000-0003-0619-5235

(c) This is an Open Access article distributed under the terms of the Creative Commons Attribution Non-Commercial License (http://creativecommons.org/ licenses/by-nc/3.0) which permits unrestricted non-commercial use, distribution, and reproduction in any medium, provided the original work is properly cited. the implementation of a new EHR (Epic Systems Co.). For all three practice settings, this new EHR was a replacement, as all locations had previously been operating with various "homegrown” EHR systems prior to Epic implementation. Endoscopic procedure volumes at the three practice settings range from 650 to 900 cases monthly.

Observational and survey data were collected from consecutive upper endoscopies and screening colonoscopies at each site prior to and after implementation of the replacement EHR at each of the three sites. Primary outcomes were aggregate survey results from endoscopy unit physicians and nurses regarding patient safety and staff satisfaction. Secondary outcomes included retrospective analyses of procedure time, changes in time spent directly monitoring patients and adverse event rate. Total procedure time ("scope-in time") was collected, as in-room time was not recorded prior to use of the new EHR. Recorded hypoxia event rate (pulse oximetry less than 92\%) was used as a surrogate marker of an adverse event. Through the review of in-room video monitoring before and after new EHR, nurse time spent directly monitoring the patient was measured as the percent of time in the room spent facing the patient or their electronic vital sign monitor. Physicians and nurses were surveyed regarding subjective safety and work satisfaction in the suite at one and six months after implementation of the EHR. Statistical analysis of this data included the use of Student's $t$-test, Fisher's test, and means calculations using SAS/STAT ${ }^{\circledR}$ (SAS Institute Inc., Cary, NC, USA).

Mean survey scores of 45 endoscopy providers, including 25 attending gastroenterologists and 20 nurses at the three facilities, are shown in Table 1 and as well on a Likert scale (Fig. 1). As these data show, staff perceptions of patient safety and job satisfaction were poor after the new EHR implementation. Endoscopy nurse perceptions were poorer than that of 
Table 1. Average Responses to Each of the Six Survey Questions from Surveyed Endoscopy Staff. All Question Responses Were Scaled from 1 (Improved) to 5 (Worse)

\begin{tabular}{lcccccc}
\hline & Question 1 $^{\text {a) }}$ & Question 2 $^{\text {b) }}$ & Question 3 $^{\text {c) }}$ & Question 4 $^{\text {d) }}$ & Question 5 $^{\text {e) }}$ & Question 6 $^{\text {() }}$ \\
\hline Endoscopist & 3.5 & 4.2 & 4.5 & 3.0 & 4.0 & 4.4 \\
Nurse & 4.6 & 4.7 & 4.9 & 3.2 & 4.6 & 4.5 \\
Combined & 4.1 & 4.2 & 4.7 & 3.1 & 4.3 & 4.5 \\
\hline
\end{tabular}

${ }^{\text {a) }}$ One month after implementation of the new electronic health record (EHR), patient safety was:

${ }^{b)}$ One year after implementation of the new EHR, patient safety was:

${ }^{c}$ Since the new EHR, the amount of time you spend with patients is:

${ }^{d)}$ Since the new EHR, the likelihood of an adverse event occurring is:

${ }^{\text {e) }}$ Since the new EHR, my job in endoscopy is:

${ }^{\mathrm{f}}$ Since the new EHR, the time required to complete a single procedure is:

$$
\text { Improved No change Worse }
$$

One month after new EHR, patient safety was:

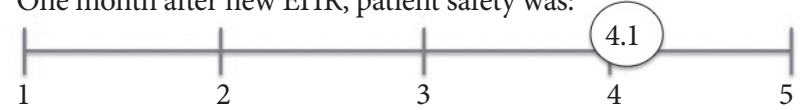

One year after new EHR, patient safety was:

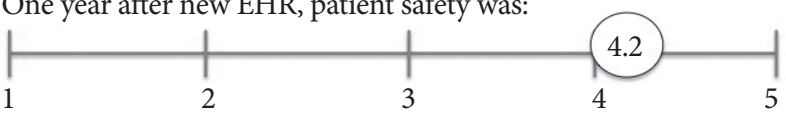

Since new EHR, amount of time spent with patients is:

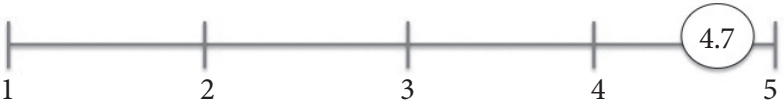

Since new EHR, likelihood of adverse events are:

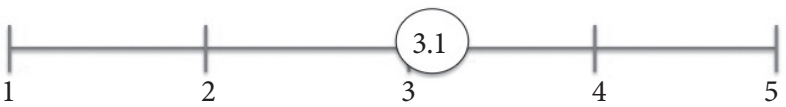

Since new EHR, my job in endoscopy is:

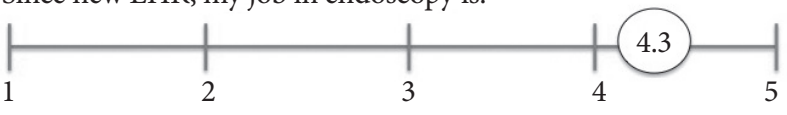

Since new EHR, time required to complete a single procedure is:

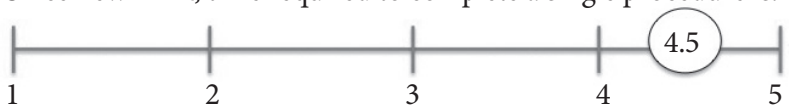

Fig. 1. Mean responses of endoscopy staff (physician and nurse) to each of the six survey questions shown on a Likert scale. On this scale, 1 point indicates that the parameter in question has "improved" and 5 points indicates it to be "worse" since electronic health record (EHR) implementation.

physicians across all queries. The total number of procedures performed at all locations over the six months after the EHR go-live was intentionally reduced by $8.3 \%$, compared to the preceding six months. Over 300 consecutive cases, procedure time significantly increased after implementation of the new EHR at one month (18 min vs. $24 \mathrm{~min}, p=0.004)$, which persisted at six months (18 $\mathrm{min}$ vs. $22.2 \mathrm{~min}, p=0.015$ ). Percentage of time monitoring the patient in the procedure room, over 50 consecutive patients, was significantly less immediately after implementation of the EHR ( $86 \%$ vs. $72 \%, p=0.033$ ). Recorded hypoxia events increased non-significantly after EHR implementation ( 28 events vs. 33 events, $p=0.59$ ).

Within academic and community settings, there are concerns among staff around patient safety, job satisfaction, and reduced direct patient contact versus time spent on the computer after the EHR transition. In our experience, these sentiments occurred despite an intentional reduction in caseload; additionally, they persisted through one year after implementation. Significantly less time was spent directly observing patients after new EHR implementation and time spent performing procedures was increased, which may be due to increased computer input requirements of staff during procedures. These results suggest that at a minimum, increased staffing, significantly reduced caseload, and hypervigilant care are essential during the implementation of a new EHR in the endoscopy suite. These deliberate efforts should be made to reduce staff dissatisfaction and burnout and to maintain patient safety when rolling out a new EHR.

\section{Conflicts of Interest}

Christopher C. Thompson received grants from Boston Scientific, Medtronic, USGI Medical, Olympus, Apollo Endosurgery, Fractyl, GI Dynamics, Aspire Bariatrics, and Spatz. He has ownership in GI Windows and Endo-TAGSS. Other authors have no financial conflicts of interest.

\section{Author Contributions}

Conceptualization: Andrew C. Storm

Data curation: ACS

Formal analysis: ACS

Investigation: ACS

Methodology: ACS

Supervision: Marvin Ryou, Christopher C. Thompson

Writing-original draft: ACS

Writing-review\&editing: MR, CCT 


\section{REFERENCES}

1. U.S. Department of Health and Human Services. Health Information Technology (HITECH Act) [Internet]. Washington, D.C.: Office of the National Coordinator for Health Information Technology; c2009 [cited 2018 Jan 5]. Available from: https://www.healthit.gov/sites/default/files/ hitech_act_excerpt_from_arra_with_index.pdf.

2. Cheriff AD, Kapur AG, Qiu M, Cole CL. Physician productivity and the ambulatory EHR in a large academic multi-specialty physician group. Int J Med Inform 2010;79:492-500.
3. Shanafelt TD, Dyrbye LN, Sinsky C, et al. Relationship between clerical burden and characteristics of the electronic environment with physician burnout and professional satisfaction. Mayo Clin Proc 2016;91:836-848.

4. Zlabek JA, Wickus JW, Mathiason MA. Early cost and safety benefits of an inpatient electronic health record. J Am Med Inform Assoc 2011;18:169-172.

5. Desai SV, Asch DA, Bellini LM, et al. Education outcomes in a duty-hour flexibility trial in internal medicine. N Engl J Med 2018;378: 1494-1508. 